Max-Planck-Institut für demografische Forschung

Max Planck Institute for Demographic Research

Konrad-Zuse-Strasse 1 - D-18057 Rostock - GERMANY

Tel +49 (0) 3812081 - 0; Fax +49 (0) 3812081 - 202;

http://www.demogr.mpg.de

MPIDR WORKING PAPER WP 2003-034

OCTOBER 2003

\title{
Demographic trends in Sweden: \\ An update of childbearing and nuptiality through 2002
}

Gunnar Andersson (andersson@demogr.mpg.de))

This working paper has been approved for release by: Jan M. Hoem (hoem@demogr.mpg.de)

Head of the Laboratory of Contemporary European Fertility and Family Dynamics.

(c) Copyright is held by the authors.

Working papers of the Max Planck Institute for Demographic Research receive only limited review.

Views or opinions expressed in working papers are attributable to the authors and do not necessarily reflect those of the Institute. 


\title{
Max Planck Institute for Demographic Research, Konrad-Zuse-Straße 1, D-180 57 Rostock, Germany. E-mail: andersson@demogr.mpg.de.
}

29 July 2003

\section{Demographic trends in Sweden: An update of childbearing and nuptiality through 2002}

\author{
by \\ Gunnar Andersson
}

\begin{abstract}
In the present note, we display the main features of recent trends in vital familydemographic behavior in Sweden. We update previously published indexes of marriage, divorce, and childbearing risks by calendar year in order to cover the developments up trough 2002, adding another two to three years of observation to our series.
\end{abstract}

Word count, main text: 1000 words

Key words: fertility trends, nuptiality trends 


\section{Summary}

The latest trend reversal in Swedish birth rates, which occurred at the end of the 1990s, continued to manifest itself in increasing propensities for childbearing during the very first years of the $21^{\text {st }}$ Century. These increases pertain to all birth orders. Marriage propensities showed an increase as well, but this was mainly a short-term development concentrated at the turn of the Millennium. The previous long-term trend of increasing divorce risks leveled off during the first two years of the new Century.

\section{Fluctuating fertility in Sweden - at present being manifested in increasing birth rates}

During recent decades, childbearing trends in Sweden have been highly volatile. Firstbirth fertility of younger women decreased continuously from the mid-1960s to the mid-1980s. This decline was followed by a marked increase in first-birth fertility of women in their $30 \mathrm{~s}$ and $40 \mathrm{~s}$, all together reflecting a general postponement of the entry into motherhood (Figure 1). During the 1980s, birth propensities increased even for younger childless women, as well as for the older childless and for mothers at the various parities (Figures 2-3). By contrast, the 1990s were characterized by strong declines in birth risks. As in the 1980s, these trends were followed by practically all demographic sub-groups of women. Subsequently, we observe yet another uniform trend reversal at the end of the 1990s. Thus birth propensities of mothers (Figures 2-3) and of childless women aged 31 and above (Figure 1) have increased again from 1998 onwards. For younger childless women (Figure 1), we find a new trend as well: their birth propensities have remained stable during the last five years. It is interesting to note that the trend reversal in 1998-1999 is not evident if one only has access to aggregate data like the Total Fertility Rate. The TFR of Sweden was 1.50 in these two years, the lowest level ever registered for that country. (In 2002, it was 1.65.) With our presentation, we can get a picture of the underlying behavior of different subgroups of Swedish women, revealing what important changes have occurred in childbearing dynamics. 


\section{Long-term decline in the propensity to get married - but a minor upsurge in marriage formation at the turn of the century}

During the 1970s, the propensity for marriage formation decreased dramatically. It continued to decline during the subsequent two decades, though at a much more moderate pace (Figure 4). In sharp contrast to this long-term trend, we find a spectacular but temporary increase in marriage-formation propensities in 1989 in response to the introduction of new rules concerning the eligibility for a widow's pension. Interestingly, we find another temporary increase in marriage formation in 2000, but this time at a much smaller scale. Marriage propensities then increased for never-married women at all parities (Figure 5). The subsequent moderate fall-back in marriage-formation intensities of the never-married indicates that it may have been the turn of the Millennium that triggered an additional number of people to arrange for a marriage in that year.

\section{Long-term increase in Swedish divorce risks - but no further increases in 2001- 2002}

The divorce risk increased sharply in 1974 in response to liberalizing changes in the divorce legislation that became effective in that year. From the end of the 1980s, divorce risks have increased again but this time on a more regular basis (Figure 7). The increase in 1974 was mainly due to an increased propensity for divorce among childless women, while the increase from the late 1980s onwards were due to increasing divorce risks of mothers (Figure 8), who constitute the vast majority of married women. The trend of increasing divorce risks leveled off during the first two years of the $21^{\text {st }}$ Century.

\section{Our investigation}

In the present note, we have provided an update of previous presentations of trends in family-demographic behavior of women in Sweden so that we now can cover childbearing and nuptiality developments up through 2002. Trends are given in the 
manner of time series of indexes of the propensity of a woman to form a marriage, to divorce, or to give birth in a specific calendar year. The indexes are given relative to a suitable baseline year in the same manner as a price index reflects prices relative to a selected year. For example, a divorce index of 1.20 for a certain year means that the risk of divorce was 20 percent higher in that year than in our baseline year. In our calculations, we standardize for the effect of a number of demographic background variables, which means that we control for the effect of compositional changes among women over the categories of these variables. We focus explicitly on the effect of the number of children on the demographic behavior in that we present separate indexes for women at different parities.

Our calculations are based on data derived from the Swedish population registers, made available to us by Statistics Sweden. We have had access to information on the dates of all births and civil-status changes in Sweden of practically all women born in that country. We base our childbearing analyses on all women born in Sweden in 1925 onwards while our study on civil-status changes are based on women born after 1945. The registration of divorces was not fully reliable before 1968 so we chose to restrict our study on civil-status changes to the period from 1971 and onwards. We present trends in childbearing from 1961 and onwards. The present update of previous presentations (Andersson and Liu 2001) adds another two to three years of observation to the picture. For an earlier study, which also contains a thorough description of our system of period analysis, see Andersson (2001). For further information on specific aspects of the divorce dynamics in Sweden, see Andersson (1997). For corresponding information on marriage-formation patterns, see Andersson (1998). Andersson (1999) gives the similar information on childbearing dynamics in Sweden.

\section{References}

Andersson, G., 1997. The impact of children on divorce risks of Swedish women. European Journal of Population 13: 109-145.

Andersson, G., 1998. Trends in marriage formation in Sweden 1971-1993. European Journal of Population 14: 157-178. 
Andersson, G., 1999. Childbearing trends in Sweden 1961-1997. European Journal of Population 15: 1-24.

Andersson, G., 2001. Trends in childbearing and nuptiality in Sweden, 1961(71)1997. In: Tedebrand, L.-G., Sköld, P. (Eds.): Nordic Demography in History and Present-day Society. Umeå, Sweden: Umeå University, 67-100.

Andersson, G., and Liu Guiping, 2001. Demographic trends in Sweden: Childbearing developments in 1961-1999, marriage and divorce developments in 19711999. Demographic Research 5: 65-78. Updated as: Demographic trends in Sweden: Childbearing developments in 1961-2000, marriage and divorce developments in 1971-1999. Demographic Research 5: A1-A14. Available at http://www.demographic-research.org/Volumes/Vol5/3. 
Figure 1: Annual index of first-birth rates.

Swedish childless women, 1961-2002, by group of ages, standardized for exact age.

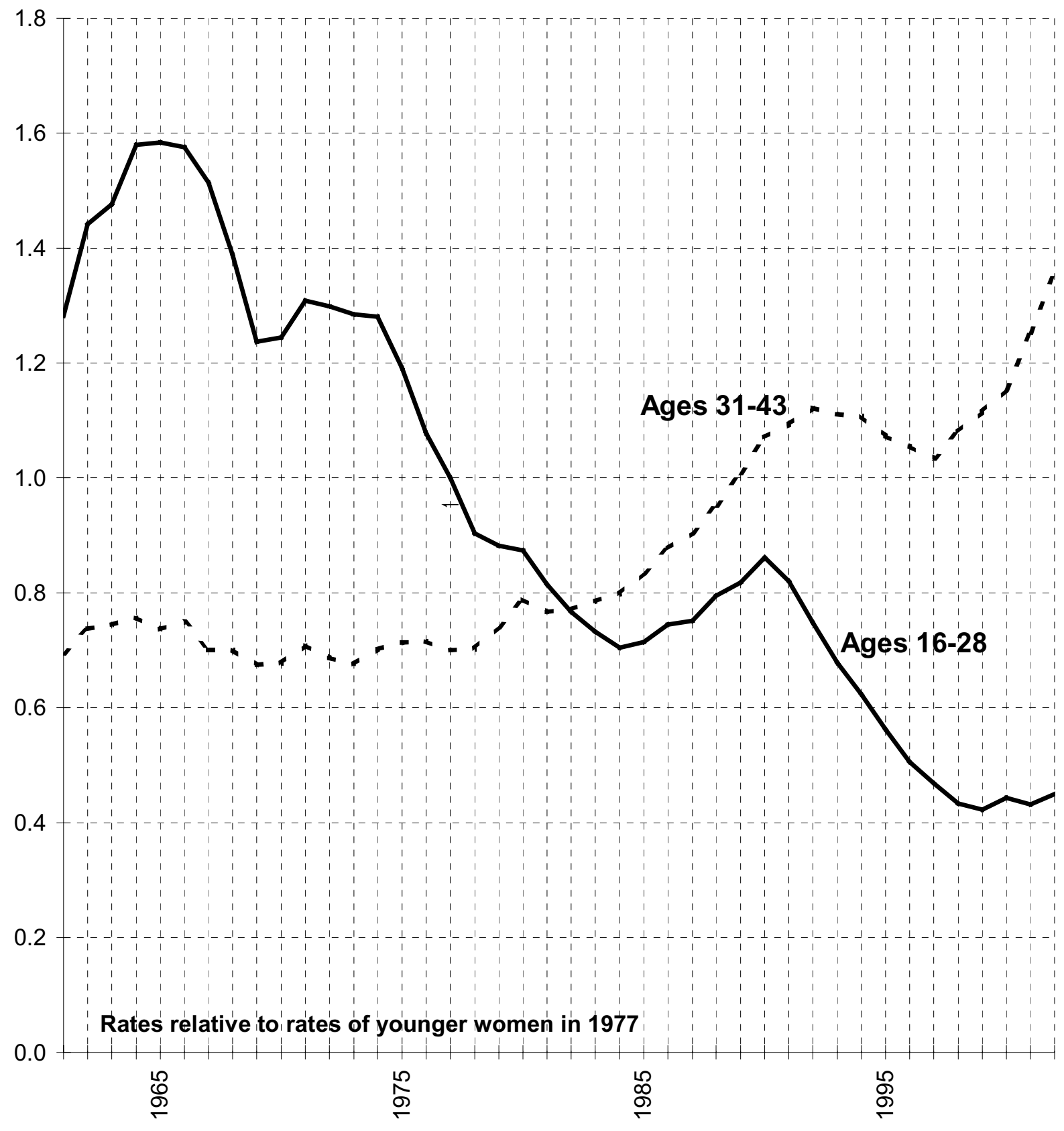


Figure 2: Annual index of second-, third-, and fourth-birth rates.

Swedish mothers, 1961-2002, by birth order,

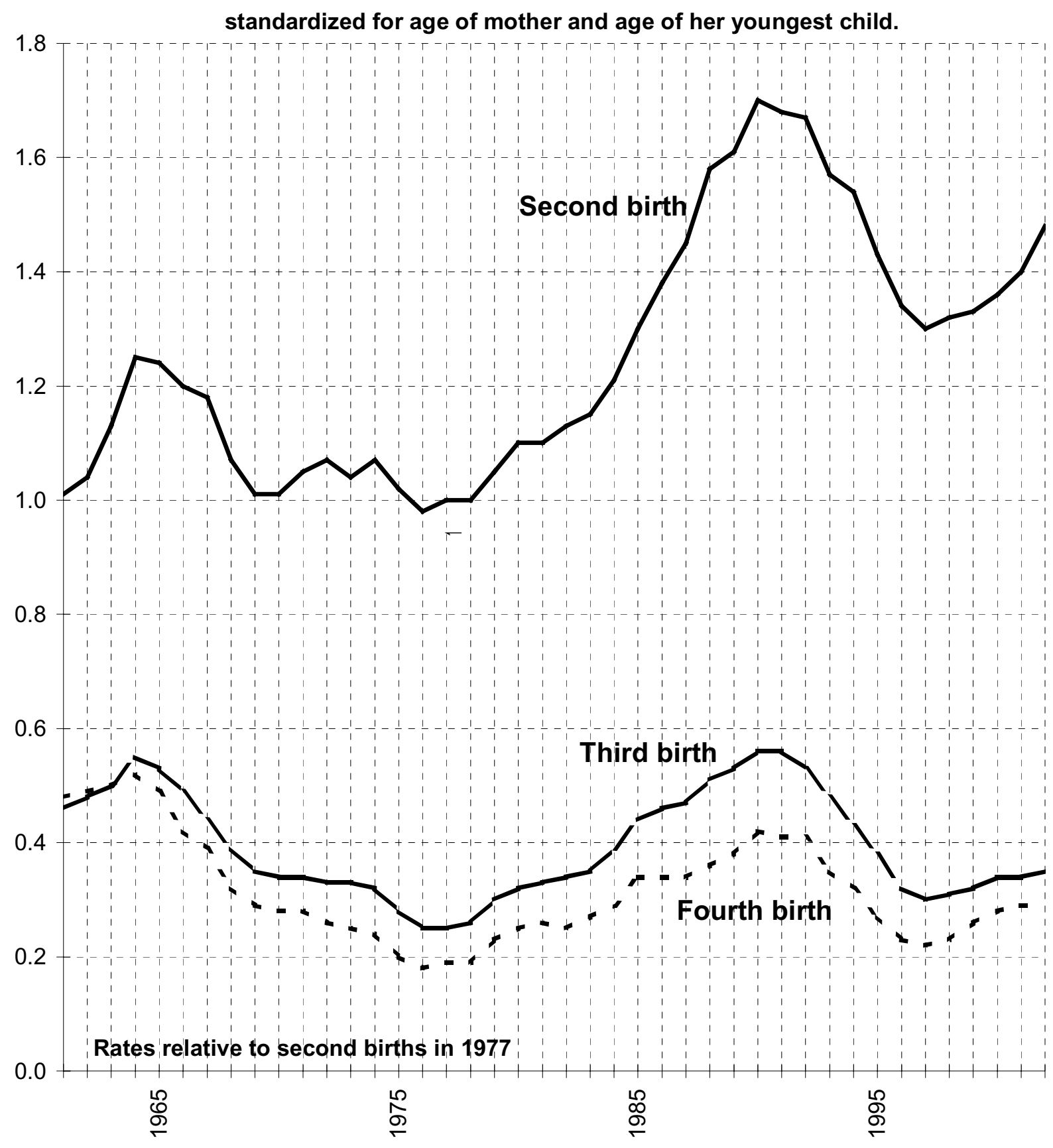


Figure 3: Annual index of second-, third-, and fourth-birth rates.

Swedish mothers, 1961-2002, by birth order,

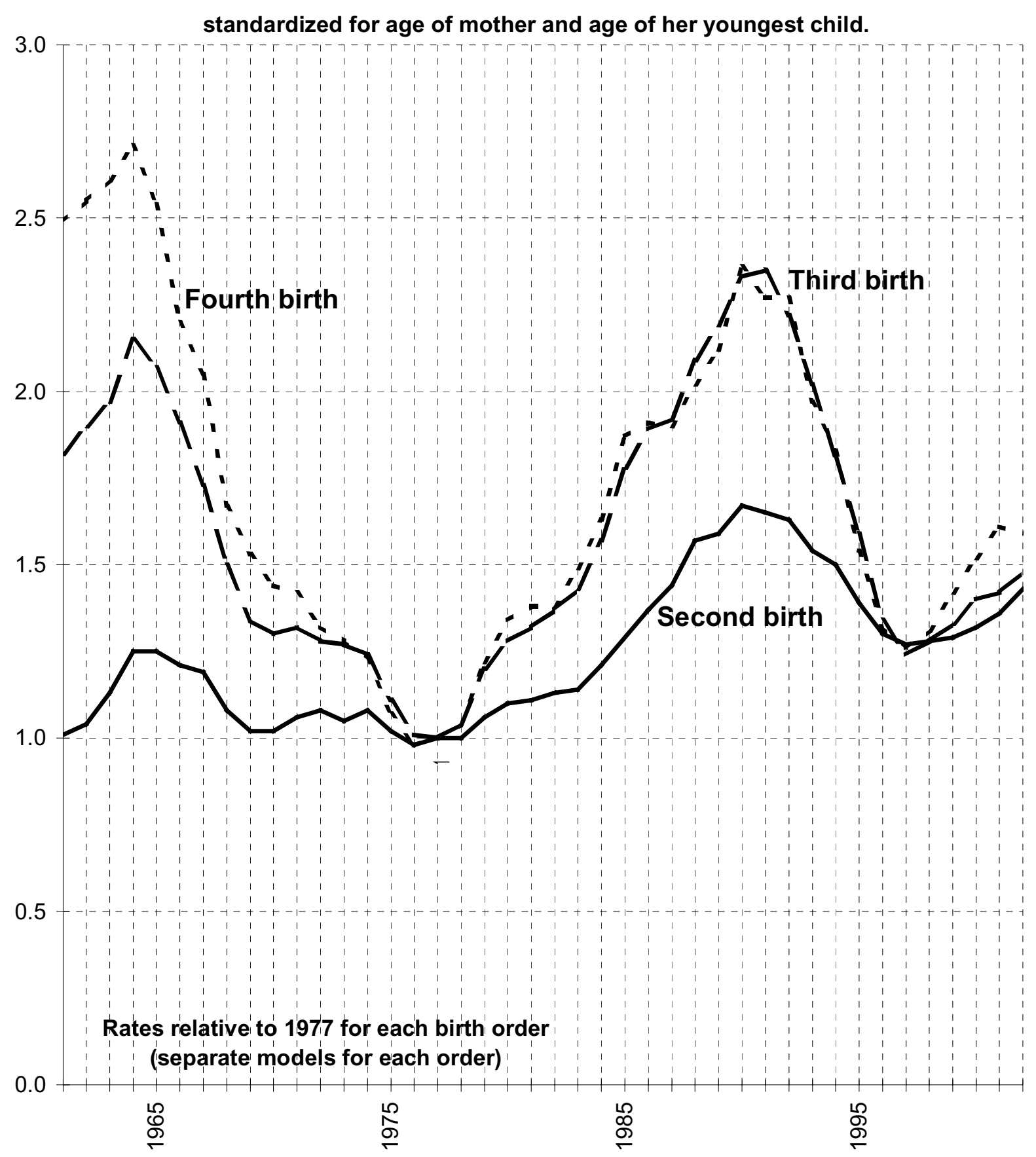


Figure 4: Annual index of marriage-risk level. Never-married Swedish women, 1971-2002, standardized for parity and age.

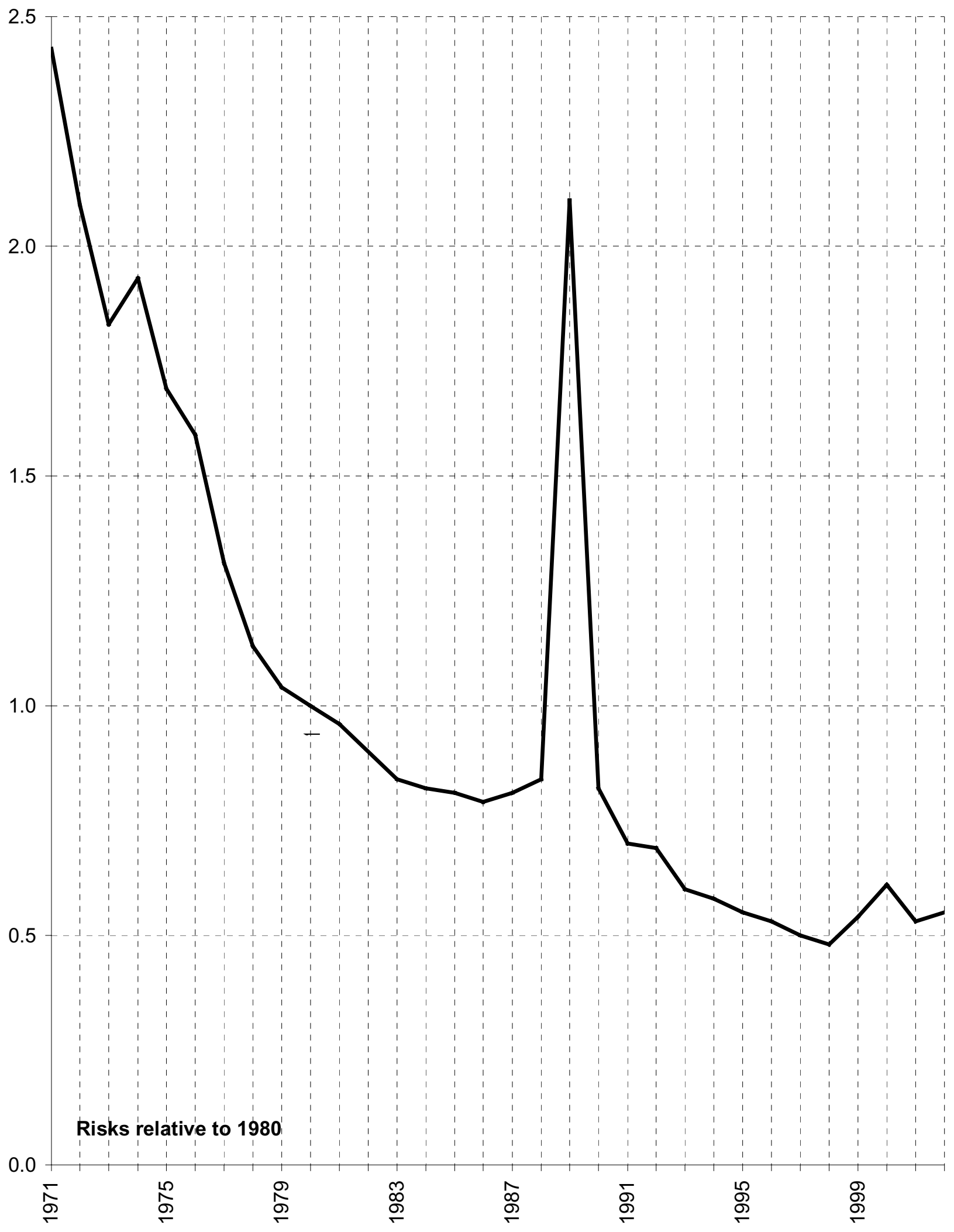


Figure 5: Annual index of marriage-risk level.

Never-married Swedish women, 1971-2002, by parity, standardized for age.

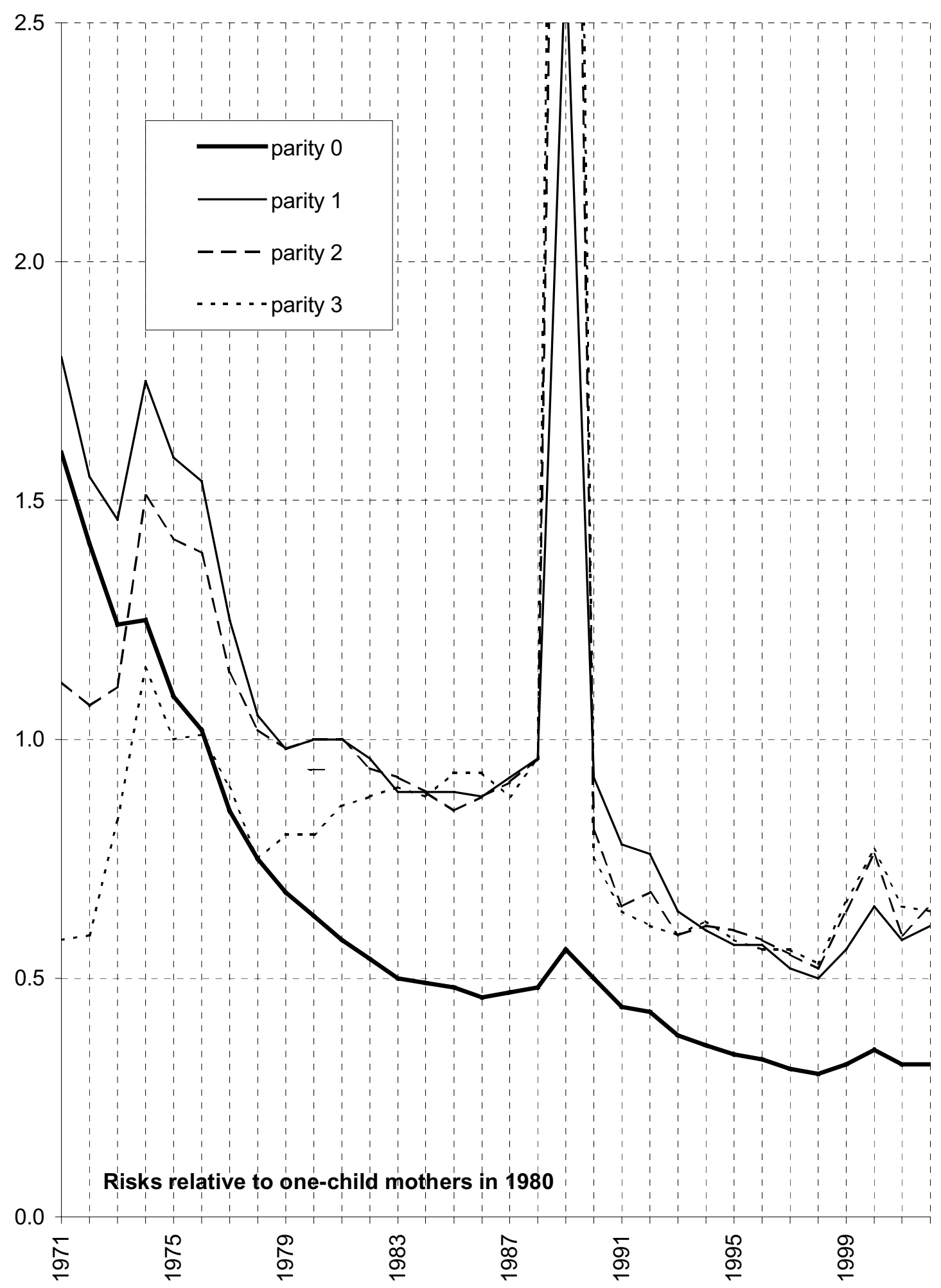


Figure 6: Annual index of remarriage-risk level.

First-divorced Swedish women, 1971-2002, by parity,

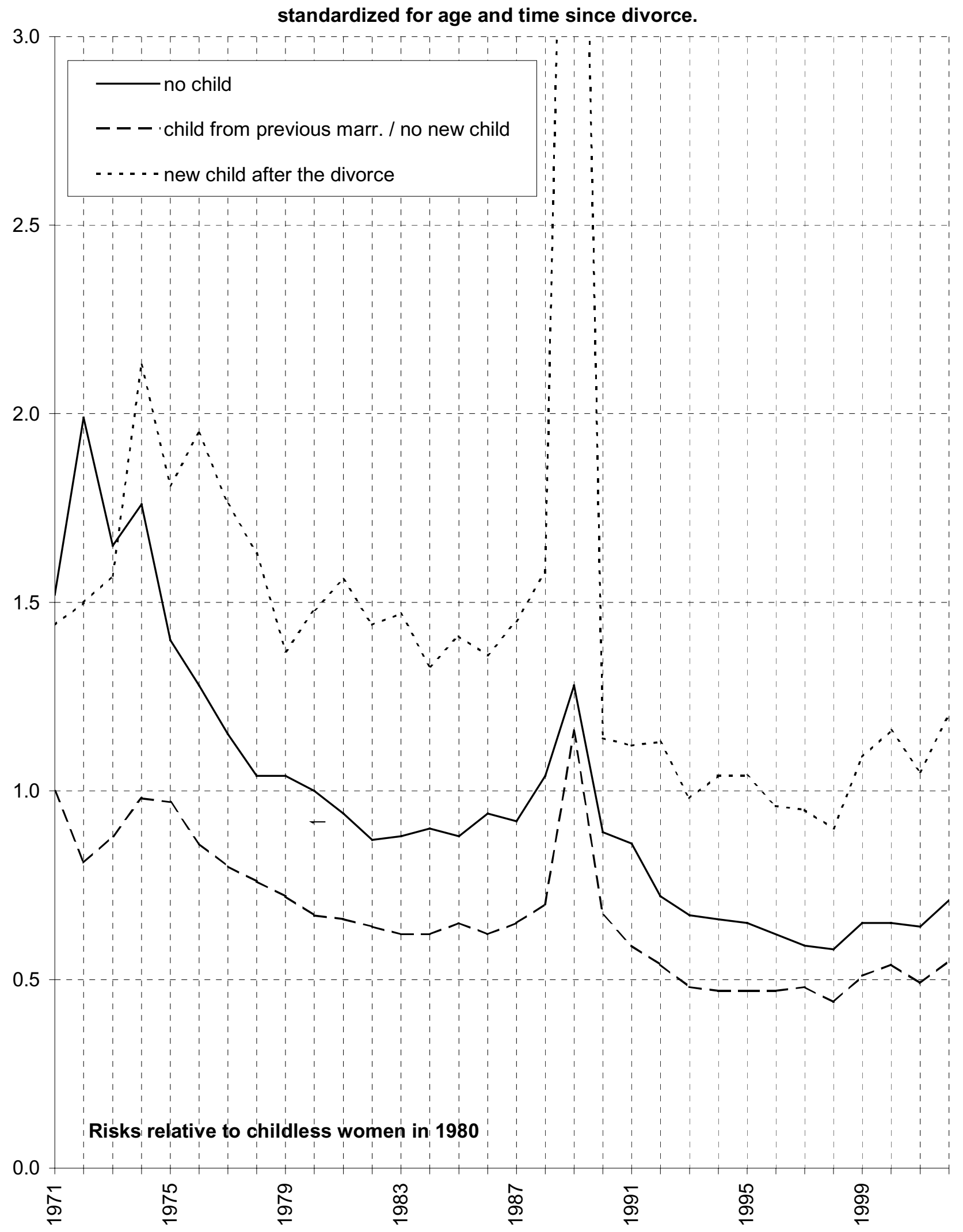


Figure 7: Annual index of divorce-risk level.

First-married Swedish women, 1971-2002,

standardized for age at marriage, parity, age of youngest child, premarital birth, and duration.

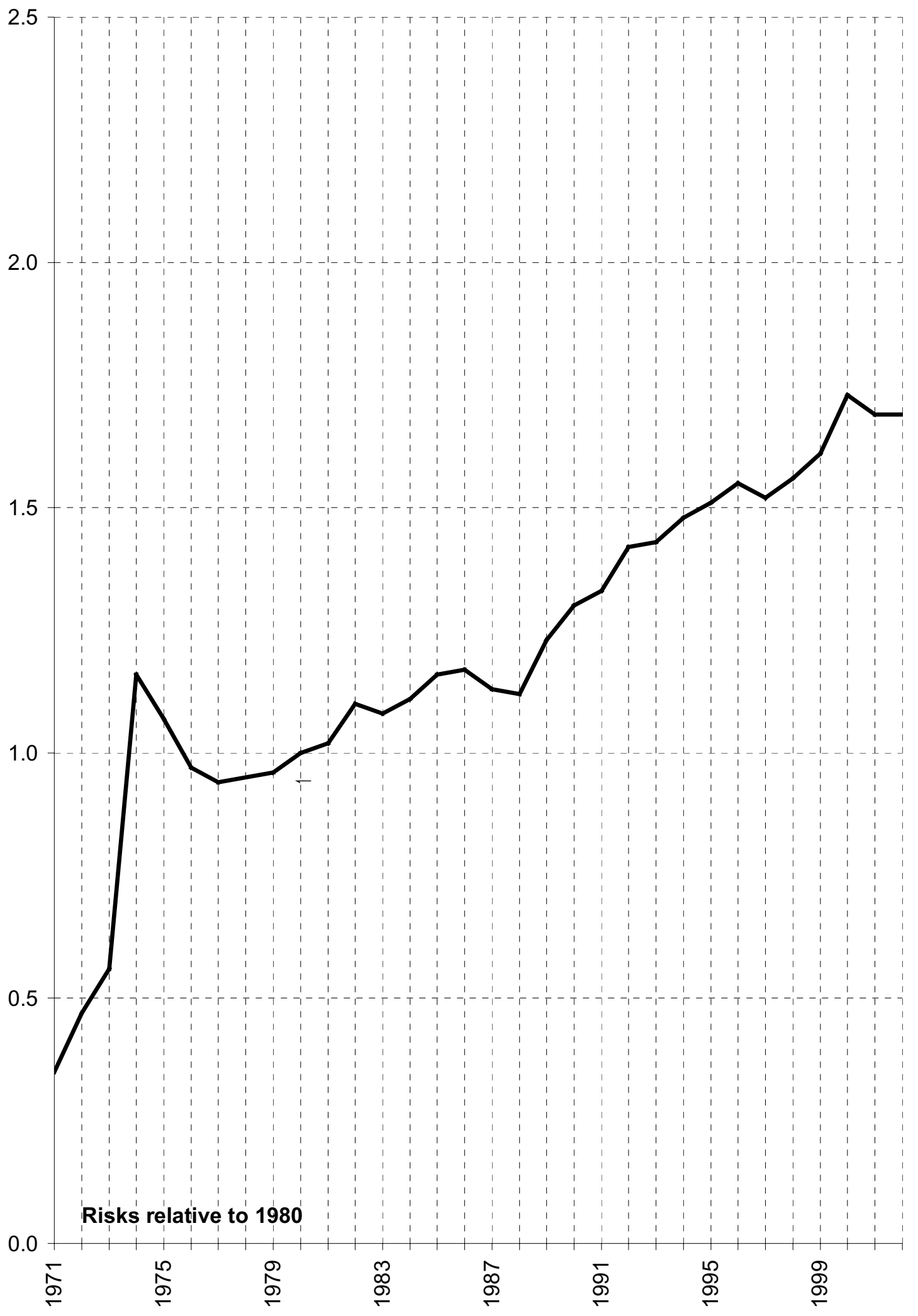


Figure 8: Annual index of divorce-risk level.

First-married Swedish women, 1971-2002, by parity,

standardized for age at and duration of marriage. Risks for mothers also

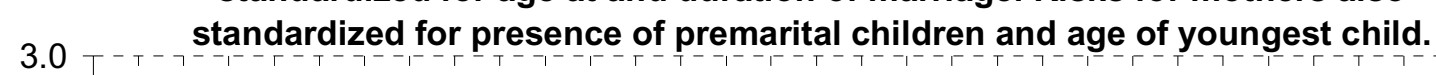

2.

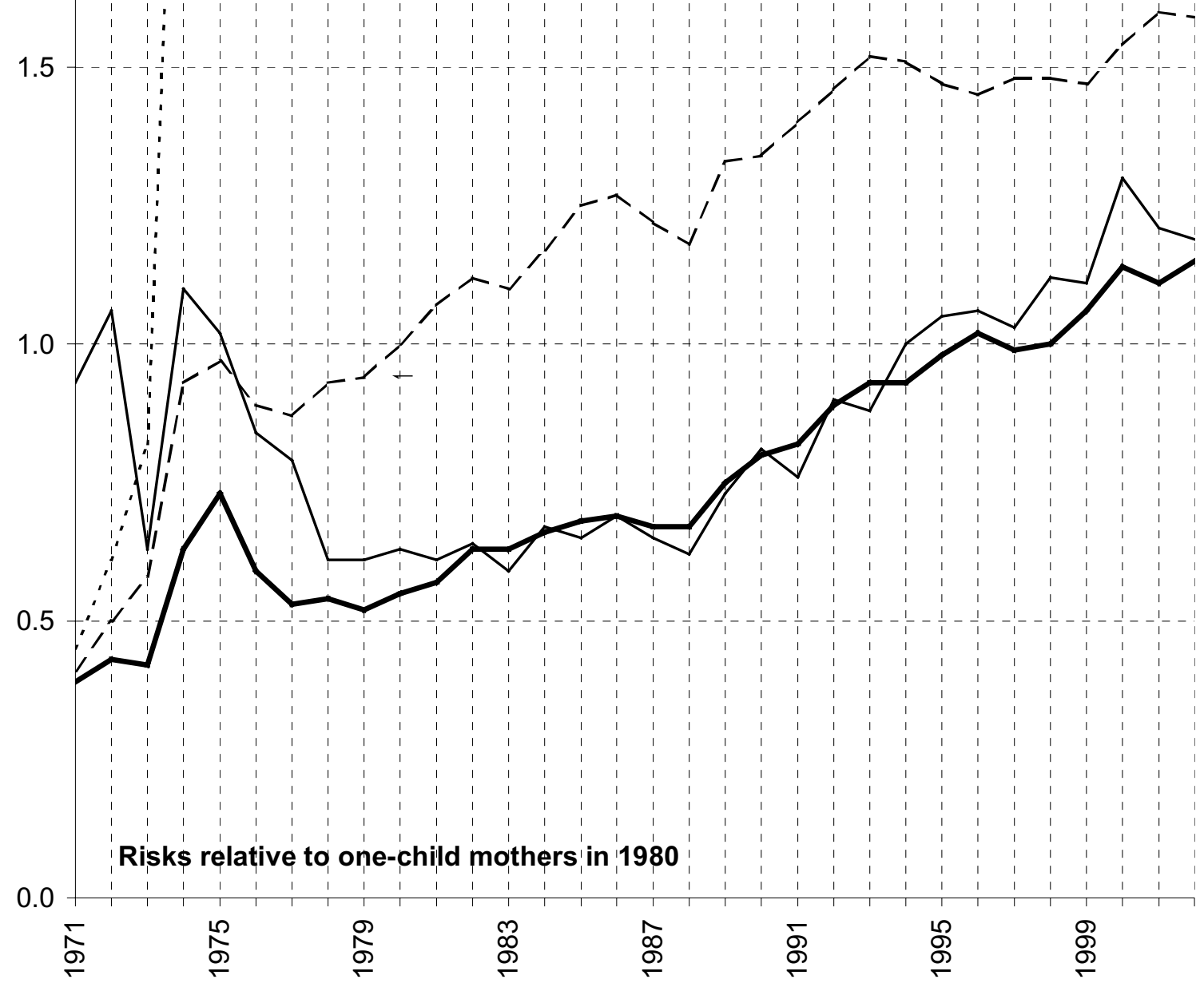

